\title{
Effects of starch sugar by-product on rumen in vitro digestibility, in situ disappearance rate, and milking productivity of the lactating dairy cow
}

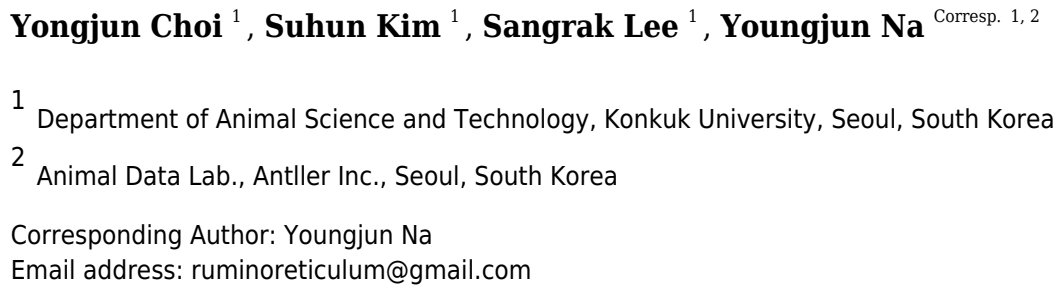

Objective. The purpose of the present study was to determine the effects of starch sugar by-product (SSB) feeding on the rumen in-vitro digestibility, in situ disappearance rate, and lactating dairy cow. Methods. To determine the rumen in vitro digestibility, $50 \mathrm{~mL}$ of the buffer-rumen fluid mixture was dispensed into a $125 \mathrm{~mL}$ serum bottle containing $0.5 \mathrm{~g}$ of dry matter (DM) of substrates. Nitrogen gas ( $\mathrm{N}_{2}, 99.9 \%$ pure) was flushed into the serum bottles and three replications were incubated at $0,2,4,8,16,24$, and $48 \mathrm{~h}$. To determine the in-situ disappearance rate, SSB was incubated for $0,2,4,8,16,24$, and 48 hours in nylon bags $(5 \times 10 \mathrm{~cm}, 45 * \mathrm{~m}$ pore size) placed within the ventral sac of two cannulated Holstein cows.. A total of sixteen Holstein Friesian cows $(60.5 \pm 20.4$ months old, $706.8 \pm 3.4$ $\mathrm{kg}$ initial body wieght) fed experimental diets during the experimental periods. The treatments were basal diet (control) and 3.0\% DM of SSB, with the diet formulated according to national research council (NRC) nutrient requirements of dairy cattle guideline. An experiment was conducted with a randomized block design for six weeks based on body weight. Results. Soluble fraction (fraction a) an of DM and crude protein (CP) was 28.99 and $11.92 \% D M$, fraction b of DM and CP was 44.63 and $31.61 \%$ DM, and C value of DM and CP was 26.38 and $56.47 \% \mathrm{DM}$. As an increase SSB level in total mixed ration (TMR), there was a decrease in gas production at 0,16 , and $48 \mathrm{~h}(\mathrm{p}<0.05)$. As an increase SSB level in TMR, there was a decrease in acetate to propionate ratio at $8,16,24$, and $48 \mathrm{~h}(\mathrm{p}<0.05)$. Dry matter intake, milk production, and milk composition did not differ between the treatments. All blood profile contents did not differ between treatments.

Conclusion. A diet containing 3.0\% SSB could be fed to ruminants without adverse effects on rumen fermentation. 


\section{Effects of starch sugar by-product on rumen in vitro}

2 digestibility, in situ disappearance rate, and milking

3 productivity of the lactating dairy cow

4

5

6 Yongjun $\mathrm{Choi}^{1}$, Suhun $\mathrm{Kim}^{1}$, and Sangrak Lee ${ }^{1}$, Youngjun $\mathrm{Na}^{1,2}$

7

$8{ }^{1}$ Department of Animal Science and Technology, Konkuk University, Seoul, South Korea

$9 \quad{ }^{2}$ Animal Data Lab., Antller Inc, Seoul, South Korea

10

11 Corresponding Author:

12 Youngjun $\mathrm{Na}^{1,2}$

13 120, Neungdong-ro Gwangjin-gu, Konkuk University, Seoul, 05029. South Korea

14

15

Email address: ruminoreticulum@gmail.com 


\section{Abstract}

18 Objective. The purpose of the present study was to determine the effects of starch sugar by-

19 product (SSB) feeding on the rumen in-vitro digestibility, in situ disappearance rate, and

20 lactating dairy cow.

21 Methods. To determine the rumen in vitro digestibility, $50 \mathrm{~mL}$ of the buffer-rumen fluid mixture 22 was dispensed into a $125 \mathrm{~mL}$ serum bottle containing $0.5 \mathrm{~g}$ of dry matter (DM) of substrates.

23 Nitrogen gas $\left(\mathrm{N}_{2}, 99.9 \%\right.$ pure) was flushed into the serum bottles and three replications were 24 incubated at $0,2,4,8,16,24$, and $48 \mathrm{~h}$. To determine the in-situ disappearance rate, SSB was 25 incubated for $0,2,4,8,16,24$, and 48 hours in nylon bags $\left(5 \times 10 \mathrm{~cm}, 45^{*} \mathrm{~m}\right.$ pore size $)$ placed 26 within the ventral sac of two cannulated Holstein cows.. A total of sixteen Holstein Friesian 27 cows (60.5 \pm 20.4 months old, $706.8 \pm 3.4 \mathrm{~kg}$ initial body wieght) fed experimental diets during the experimental periods. The treatments were basal diet (control) and 3.0\% DM of SSB, with the diet formulated according to national research council (NRC) nutrient requirements of dairy cattle guideline. An experiment was conducted with a randomized block design for six weeks

31 based on body weight.

32 Results. Soluble fraction (fraction a) an of DM and crude protein (CP) was 28.99 and 11.92 $33 \% \mathrm{DM}$, fraction $\mathrm{b}$ of DM and CP was 44.63 and $31.61 \% \mathrm{DM}$, and c value of DM and CP was 3426.38 and 56.47 \%DM. As an increase SSB level in total mixed ration (TMR), there was a 35 decrease in gas production at 0,16 , and $48 \mathrm{~h}(\mathrm{p}<0.05)$. As an increase SSB level in TMR, there 36 was a decrease in acetate to propionate ratio at $8,16,24$, and $48 \mathrm{~h}(\mathrm{p}<0.05)$. Dry matter intake, 37 milk production, and milk composition did not differ between the treatments. All blood profile 38 contents did not differ between treatments. 
39 Conclusion. A diet containing 3.0\% SSB could be fed to ruminants without adverse effects on 40 rumen fermentation.

41

42 Keywords: Feed value, Starch sugar by-product, Rumen in vitro digestibility, In situ

43 disappearance rate, Lactating dairy cow 


\section{Introduction}

46 Recycling by-products could minimize environmental problems and help reduce livestock

47 production costs (Bocquier and González-García, 2010). Refined starch is generally obtained

48 from grains and it has been processed as various saccharides (modified starch) with glucose,

49 oligosaccharide, or syrup (Gaffney, 2008). Since the starch industry is growing in recent years,

50 more waste must be processed. Accordingly, it is necessary to conduct research on the recycling

51 - of starch sugar by-products.

52 The starch sugar by-product (SSB) is produced by the following process: 1) liquid starch passes

53 through the filter to absorb useful saccharides into the center and 2) residue remains on the

54 surface, which is separated using the knife (Kato, 1993). Sugar contents is present in the residue

55 following the extraction of starch sugar from the filter (James, 2008). Furthermore, since the

56 filter is constructed of silica ( $\mathrm{SiO} 2)$, SSB does not only contain sugar but also some silica, which

57 is mixed during the cutting process of the filter (Rabelo et al., 2015). Although many types of

58 studies have been performed regarding the effect of starch in ruminants (Huntington, 1997; Mills

59 et al., 1999; Ortega Cerrilla and Mendoza Martínez, 2003; Harmon et al., 2004; Svihus et al.,

60 2005), the studies of silica have not been as many as those of starch. Silica is known to be

61 involved in the early stages of bone formation in animals, there was reported that it has effects on

62 decreased cell wall digestibility of forage feed in ruminants (Soest, 1994). As a food additive,

63 silicon dioxide is widely used, and no adverse effects have been reported in animals (Younes et

64 al., 2018). Despite the fact that silica has been fed without negative effects in ruminants through

65 forage and additives, it is important to determine whether it has negative effects on nutritional

66 aspects when SSB is used as a feed ingredient in ruminants. Furthermore, studies on starch sugar

67 by-products are rare in ruminants. 
68 Therefore, the objectives of the present study were to analyze the physicochemical

69 characteristics of SSB and to determine the effect of SSB level on rumen in vitro digestibility

70 and in situ disappearance rate. In addition, we determined the effect of the SSB on the milk

71 productivity of dairy cows. 


\section{Materials \& Methods}

74

\section{Starch sugar by-product}

The SSB used in the experiment originated from the starch sugar factory of Daesang

77 Industry (Fig 1; 884, Oehang-ro, Gunsan-si, Republic of Korea). As the physical properties can

78 be affected by variations in the production process, the SSB samples were collected 10 times for

795 weeks and stored at $-20^{\circ} \mathrm{C}$ until the experiment was conducted. The distribution, variation and

80

82

83

84 chemical composition, fatty acid composition, and amino acid composition of SSB were shown in Table 1, A1, and A2, respectively.

\section{Rumen in vitro digestibility and in situ disappearance rate}

The experiment was carried out in the experimental farm at Pyeongchang-gun, Gangwon-do, South Korea (latitude $37.54^{\circ}$ and longitude $128.44^{\circ}$ ). Two ruminally cannulated Holstein Friesian cows were assigned for rumen fluid collection and fed commercial concentrate pellet (dry matter [DM], 92.3\%; crude protein [CP], 14.5\% of DM; neutral detergent fiber [NDF], 31.8\% of DM; acid detergent fiber [ADF], 11.6\% of DM; ether extract [EE], 3.7\% of DM; ash, 7.5\% of DM) and rice straw (DM, 92.1\%; CP, 5.5\% of DM; NDF, $62.1 \%$ of DM; ADF, $36.6 \%$ of DM; EE, $1.4 \%$ of DM; ash, $5.2 \%$ of DM) ad libitum during the experiment. In the rumen in vitro digestibility test, McDougall's buffer (McDougall, 1948), which is continuously purged with $\mathrm{CO}_{2}$ at $39^{\circ} \mathrm{C}$ before usage, was mixed with rumen fluid at a 4:1 ratio (v/v). The total mixed ration (TMR) with $\operatorname{SSB}(0,2,4,6$, and $8 \% \mathrm{DM})$ samples were dried and milled to pass through a 1-mm screen (Wiley Mill; Thomas Scientific, USA) and chemical composition showed in Table 2 . The $50 \mathrm{~mL}$ of buffer-rumen fluid mixture was randomly dispensed into a $125 \mathrm{~mL}$ serum bottle filled with $0.5 \mathrm{~g}$ DM of substrates and the experimental 
97 unit was each serum bottle. $\mathrm{N}_{2}$ gas $(99.9 \%$ pure) was flushed into headspace of the serum bottles 98 and three replications were incubated at $0,2,4,8,16,24$, and $48 \mathrm{~h}$. Two ruminally cannulated Holstein cows were assigned for in situ disappearance rate measurements test. Dry matter, CP, EE, NDF, ADF, ash, and water-soluble carbohydrate (WSC) contents of SSB were $61.4,14.4,23.26,35.7,31.3,32.6$, and $9.96 \%$ of DM, respectively. The

102 dried SSB samples were ground and screened using a 1-mm sieve prior to use in the experiment 103 (Thomas Scientific, NJ, USA). A total of 21 nylon bags $(5 \times 10 \mathrm{~cm}, 45 \mu \mathrm{m}$ pore size; R510; ANKOM Inc.,NY, USA) containing $5 \mathrm{~g}$ of SSB have been placed in each rumen ventral sacs of two cannulated Holstein cows. These bags were incubated for $0,2,4,8,16,24$, and 48 hours according to national research council (NRC) nutrient requirements of dairy cattle guidelines (NRC, 2001) in three replicate. After incubation, the nylon bags were washed in tap water, dried at $60^{\circ} \mathrm{C}$ for $48 \mathrm{~h}$, and then weighed for DM and CP analysis. Disappearance rate was assessed using the formula of Ørskov (Menke et al., 1979) follow described in Choi et al. (2021). The 110 following formula:

$\mathrm{P}=a+b\left(1-\mathrm{e}^{-\mathrm{ct}}\right)$

112 , where $\mathrm{P}$ is the actual degradation after time $\mathrm{t}$; $a$ is the intercept of the degradation curve at time 113 zero; $b$ is the potential degradability of the component of the protein which will, in time, be 114 degraded; $c$ is the rate constant for the degradation of $b$; and $t$ is time. Regression analysis was 115 performed using SAS PROC REG (Version 9.4; SAS Institute Inc., NC, USA) for estimation of 116 the fraction $b$.

117 The effective degradability (ED) of DM and CP was calculated using the following 118 equation described in Choi et al (2021):

$119 \mathrm{ED}=a+(b \times c) /(c+k)$, 
120 where $k$ is the estimated rate of outflow from the rumen and $a, b$, and $c$ are the same parameters

121 as described above. The ED was estimated as ED2, ED5, and ED8 assuming rumen solid outflow

122 rates of $0.02,0.05$, and $0.08 / \mathrm{h}$, which are representative of low, medium, and high feeding intake,

123 respectively.

124

125 Animal study method and experimental design

Animal research protocols were approved by Konkuk University Animal Care and Use

127

128

129

130

131

132

133

134

135

136

137

138

139

140

141

142

Committee (approval number: KU16139).

A total of sixteen Holstein Friesian cows (60.5 20.4 months old, $706.8 \pm 3.4 \mathrm{~kg}$ initial BW)

fed experimental diets (Table 3) during the entire experimental periods. Experimental animals were the commercial breed and obtained from Konkuk University experimental farm (latitude, $37.06^{\circ}$ and longitude, $127.86^{\circ}$ ). The average temperature and relative humidity were $25.3 \pm 4.2^{\circ} \mathrm{C}$ and $45.6 \pm 11.57 \%$ during the entire experimental periods, respectively. Cows were allocated according to milk yield, parity, and days in milk and then allotted into six sawdust-bedded pens (two or three head/pen; $5 \mathrm{~m} \times 10 \mathrm{~m}$ ) with an individual feeding gate. The treatments were basal diet (control) and 3.0\% DM of SSB (experimental), with the diet formulated according to NRC (Table 3). The feeding trial was conducted as a randomized complete block design for six weeks, which included two weeks of individual feeding gate adaptation, four weeks of adaptation to the experimental diet, and two weeks for data collection. Experimental diets were fed twice a day at 0800 and $1600 \mathrm{~h}$ in form of a TMR. Experimental diets, water, and mineral block were fed adlibitum. The experimental animals were not euthanized after the end of the experiment, they have continuously raised after moving to a commercial farm as healthy.

Peer) reviewing PDF | (2021:10:66383:1:1:NEW 10 Jan 2022) 


\section{Physical and chemical analysis}

144 Complex viscosity was analyzed using a rotational rheometer (DHR 1; TA instrument Ltd.,

145 DE, USA) at conditions of 0.1 to $100 \mathrm{~Hz}$ frequency and $20^{\circ} \mathrm{C}$. The particle size was determined

146 by laser diffraction and scattering using particle size analyzer (LS 13-320; Beckman coulter, CA,

147 USA). Density of dried sample was analyzed using gas pycnometer (AccuPyc II 1340;

148 Micromeritic Instrument Corporation, GA, USA).

149 All samples were dried in a drying oven (HB-503-LF; Hanbaek scientific technology,

150 Buchun-si, Republic of Korea) at $60^{\circ} \mathrm{C}$ for $48 \mathrm{~h}$. Dry matter (DM; method No. 937.01), crude

151 protein (CP; method No. 990.03), ether extract (EE, method No. 920.39), ash and silica (method

152 No. 920.08) were analyzed according to AOAC method (AOAC, 2005). Neutral detergent fiber

153 (NDF; method No. 2002.04) and acid detergent fiber (ADF; method No. 973.18) were analyzed

154 with ANKOM Fiber Analyzer (A200; Ankom Inc., NY, USA) according to method of Van Soest

155 et al (Van Soest et al., 1991). Water soluble carbohydrate (WSC) was extracted using method of

156 Kerepesi and Boross (Kerepesi et al., 1996) and was analyzed using phenol sulfuric acid method

157 (Nielsen, 2017). Gross energy (GE) was determined using automatic bomb calorimeter (Parr

1581261 bomb calorimeter; Parr Instruments Co., IL, USA). Gas production was measured with a 50

159 mL glass syringe (Hypodermic Glass Syringe; DHS Medical Co., Seoul, Republic of Korea).

160 The $\mathrm{pH}$ values were measured using $\mathrm{pH}$ meter (Orion Dualster-F, Thermo fisher scientific, NJ,

161 USA). Ammonia nitrogen was determined as previously described in Choi et al. (2019)

162 according to a method of Chaney and Marbach (Chaney and Marbach, 1962). The volatile fatty

163 acid (VFA) was identified as previously described in Choi et al. (2019) using gas

164 chromatography (HP 6890; Agilent Technologies, CA, USA) equipped with an Omega Wax 
165 Fused Silica Capillary column (Length, $30 \mathrm{~m} 0.3 \times 2 \mathrm{~mm}$ Df, $0.25 \mu \mathrm{m}$; Sigma-Aldrich Co, MO,

166 USA) and flame ionization detector. The carrier gas was used He gas in gas chromatography.

167

168 Fatty acid composition analysis

169

For fatty acid (FA) analysis, SSB samples were extracted using a chloroform to

170

methanol (2:1, v/v) solvent (Floch, 1957) and then methylated (Lepage and Roy, 1986).

171 Methylated supernatant was injected into a gas chromatograph (Agilent 6890, NY, USA)

172 equipped with a flame ionization detector and a capillary column $(30 \mathrm{~m} \times 0.25 \mathrm{~mm} \times 0.25 \mu \mathrm{m}$; No.

173 122-3232, Agilent, NY, USA) operated at $50^{\circ} \mathrm{C}$ in the oven (Garces and Mancha, 1993). The

174 inlet and detector temperatures were 180 and $250^{\circ} \mathrm{C}$, respectively. Helium was used as a carrier

175 gas.

176

\section{Amino acid composition analysis}

178

To determine concentrations of amino acids (AAs) in SSB, each sample was placed in a

volumetric flask to which was added $30 \mathrm{ml}$ of $6 \mathrm{~N} \mathrm{HCl}$. Then, the flask was hydrolyzed at $130^{\circ} \mathrm{C}$

for $24 \mathrm{~h} \mathrm{min.} \mathrm{The} \mathrm{extracts} \mathrm{were} \mathrm{then} \mathrm{passed} \mathrm{through} \mathrm{a} 0.45 \mu \mathrm{m}$ filter. For subsequent analysis,

HPLC (Ultimate 3000, Thermo Fisher Scientific Inc., USA) was used as described by method of

182 Henderson et al (Henderson et al., 2000).

183

\section{Milk yield, milk composition, and blood profiles}

Milk yield was collected previously described in Choi et al. (2019) using a tandem milking system (Milking Parlor Auto Tandem, GEA Co., Düsseldorf, Germany) twice a day at 0300 and 1500 during the entire experimental period. Milk samples were collected in $20 \mathrm{~mL}$ tubes using 
188 the sampling port of a milking machine every week and stored at $4^{\circ} \mathrm{C}$. Before milk sampling,

189 Anti-corrosive agents (Broad spectrum micro tabs II, Advanced Instrument Inc., MA, USA) were

190 added to prevent any chemical changes until the analysis of the milk composition. The milk

191 composition was evaluated previously described in Choi et al. (2019) using near-infrared

192 spectrophotometer (Milko-scan FT 6000, Foss electric Co., Hilleroed, Denmark).

193 Blood samples were collected at d 28 and d 42 after the end of the adaptation period. Blood 194 samples were collected as previously described in Choi et al. (2021) via the jugular vein using 195 18-gauge needles and transferred to silicon-coated serum tubes (15 mL Vacutainer, BD, Franklin 196 Lakes, NJ, USA). The serum and plasma were obtained by centrifugation at $1,000 * \mathrm{~g}$ at $4^{\circ} \mathrm{C}$ for 19715 minutes. Serum was stored at $-70^{\circ} \mathrm{C}$ until analysis and chemical compositions of serum were 198 analyzed using an chemical analyzer (Model 7180 Clinical Analyzer; Hitachi Ltd, Tokyo, Japan) 199 following the manufacturer's manual. Reagents were purchased from commercial products (JW 200 Medical, Seoul, Korea) to determine glucose, blood urea nitrogen (BUN), glutamic oxaloacetic 201 transaminase (GOT), and glutamic pyruvate transaminase (GPT), and $\gamma$-glutamyltransferase 202 (GGT). White blood cell, red blood cell, hematocrit, hemoglobin, and platelet were determined 203 using hematology analyzer (VetScan HM2, Abaxix Inc., 333 Fiske St, Holliston, MA, USA). 204

\section{Statistical analysis}

Data were analyzed using a MIXED procedure of SAS package program (SAS Inst.

207 Inc., Cary, NC, USA) as a randomized completely block design. The model was,

$208 \mathrm{Y}_{\mathrm{i}(\mathrm{t})}=\mu+\mathrm{T}_{\mathrm{i}}+\mathrm{E}_{\mathrm{i}(\mathrm{t})}$,

209 where $\mu$ is average value, $T_{i}$ is treatment value and $E_{i(t)}$ is the error value. The fixed effect SSB

210 concentration, and random effects were not considered. Polynomial orthogonal contrasts were 
211 used to determine SSB supplementation effect using the CONTRAST option. The crossing point 212 of quadratic broken-line and the quadratic line was determined using NLIN code in order to 213 determine proper SSB concentration in feed. Pairwise comparison was performed to determine 214 SSB supplementation effect using the TTEST option. Outlier was excluded using the method of 215 interquartile range (IQR). Least squares mean between treatments were assessed using a pairwise 216 comparison method. Statistical difference and tendency were accepted at $p$-value less than 0.05 217 and 0.10, respectively. All means are presented as least square means. 


\section{Results}

220

221

222

223

224

225

226

227

228

229

230

231

232

233

234

235

236

237

238

239

240

241

Dry matter and CP degradation parameters, and the ED values of SSB are presented in Table 4. Soluble fraction $a$ of DM and CP content was 28.99 and $11.92 \%$ of DM, fraction $b$ of DM and CP content was 44.63 and $31.61 \%$ of DM, and $c$ value DM and CP content was 26.38 and $56.47 \mathrm{~h}^{-1}$. The ED2, ED5, and ED8 of DM content were 70.49, 66.54, and $63.28 \%$, respectively and those of CP content were $42.45,40.96$, and $39.61 \%$, respectively. Gas production, $\mathrm{pH}$, and ammonia nitrogen content by SSB level are presented in Table 5. As increasing incubation time, gas production was increased in all treatment groups. At 0,16 , and $48 \mathrm{~h}$, the result of gas production showed a significant difference among the treatments $(\mathrm{p}<0.05)$, and as the amount of SSB in the TMR increased, the amount of gas production was quadratically reduced at $48 \mathrm{~h}(\mathrm{p}<0.05)$. As increasing incubation time, $\mathrm{pH}$ value was decreased in all treatment groups. The $\mathrm{pH}$ value showed a significant difference at 8 and $48 \mathrm{~h}$ during the rumen in vitro digestibility $(\mathrm{p}<0.05)$. As increasing incubation time, ammonia nitrogen value was increased in all treatment groups. The ammonia nitrogen of SSB 6 and $8 \%$ treatment was lower than other treatment at 2, 4, 16, $24(\mathrm{p}<0.05)$. Total VFA, acetate, propionate, and acetate/propionate $(\mathrm{A} / \mathrm{P})$ ratio by SSB level are presented in Table 6. As increasing incubation time, total VFA, acetate, and propionate content were increased in all treatment groups. Total VFA, acetate, and propionate did not differ among the treatments. As increasing incubation time, A/P ratio was decreased in all treatment groups. As the amount of SSB in TMR increased, there was a decrease in acetate/propionate ratio at $8,16,24$, and $48 \mathrm{~h}(\mathrm{p}<0.05)$. Dry matter intake, milk production, and milk composition by SSB supplementation are presented in Table 7. Dry matter intake, milk production, and milk composition did not differ between the treatments. Blood profiles by SSB supplementation are presented in Table 8 . All blood profile contents did not differ between 
242 treatments.

Peer] reviewing PDF | (2021:10:66383:1:1:NEW 10 Jan 2022) 


\section{Discussion}

245 In the starch sugar production process, SSB is separated by the physical method such as a sharp

246 blade (figure 1) and it could have effects on the change of physical and chemical composition of

247 SSB. The physical and chemical characteristics of collected SSB showed a high degree of

248 variability in this experiment (see table 1). It is considered to be one of the factors that make it

249 difficult to use as a feed ingredient. The most ash content of SSB might be considered as silica

250 content ( $\mathrm{SiO} 2)$ in this study (see table 1), silica contents was reported that have a negative effect

251 on ruminants such as a decrease of forage utilization (Soest, 1994). Thus, this may be considered

252 a weakness in the nutritional aspects as a ruminant feed component. However, SSB has

253 comparable gross energy and similar ED value within the rumen compared to corn (Silva et al.,

254 2020). SSB is considered that have some potential as an energy-feed ingredient. Moreover, the

255 content of CP in SSB ranged from 6.01 to $33.46 \%$ of DM, indicating that it could be utilized as a

256 protein supplement (see table 1). Soybean meal is mainly used as a protein source in livestock

257 feed. Although ED value of CP in SSB (39.6 to $42.5 \%$, Table 4) was lower than those of

258 soybean meal (63 to $71 \%$, Heuzé, Tran \& Kaushik, 2015), it could be provided another option to

259 choose protein ingredients in livestock feed. During the in vitro rumen digestibility trial, the

260 amount of gas produced means those of organic digestibility by bacterial microbes (Theodorou et

261 al., 1994). Gas production showed the lowest at $48 \mathrm{~h}$ in SSB levels of 4 to $8 \%$ groups compared

262 to those of 0 and $2 \%$ groups (see table 5). There was reported that an increase of lipid sources in

263 feed has a negative effect on rumen fermentation (Johnson and Johnson, 1995). In the rumen in

264 vitro digestibility trial, as a level of SSB in the experimental feed increased, EE and ash content

265 was linearly increased (see table 2). Therefore, the decrease of gas production in the rumen in

266 vitro digestibility trial might be explained by an increase in both lipids and ash contents in the 
267 experimental feed. In addition, a level of $2 \%$ SSB based on the dry matter in feed is considered 268 to be the highest level that can be fed to animals without affecting their digestibility. Despite a 269 significant difference in $\mathrm{pH}$ level at 8 and 48 hours, the $\mathrm{pH}$ content in the rumen was within a 270 normal range (Dijkstra et al., 2012), thus the difference in $\mathrm{pH}$ alone hardly explains the negative 271 effect. However, the significant difference in ammonia nitrogen content might be mean that 272 inhibit temporarily microbial fermentation according to SSB level in the feed (Hristov and Ropp, 273 2003). Ammonia nitrogen of 8 and $10 \%$ SSB treatment were lower than those of other treatments 274 until $24 \mathrm{~h}$ (see table 5). Nevertheless, ammonia nitrogen content did not differ at $48 \mathrm{~h}$ among 275 treatments, it might consider that as degradation of organic matter in feed by the fermentation, it 276 mitigated toxicity in the rumen to microbes such as lipids (Jarvis and Moore, 2010). Totally, a 277 high amount of SSB (about 8\% over) supplementation considers that seriously inhibit rumen 278 fermentation. In the result of VFA content, SSB supplementation seems that did not inhibit 279 producing VFAs during rumen in vitro digestibility. Total VFA, acetate, and propionate did not 280 differ among treatments. However, the A/P ratio was decreased as an increase in the SSB level of 281 feed (see table 6). It means that supplementation of SSB supplied non-fibrous carbohydrates in 282 TMR (James, 2008). In other words, it considers that the SSB could be used as an energy source 283 of feed. In addition, increasing the SSB level of feed means that increasing the ratio of NFC to 284 fibrous material in the feed. It is possible to explain the decrease in the $\mathrm{A} / \mathrm{P}$ ratio of this study by 285 the fact that propionate is produced by microbes using NFC in the rumen. There was reported 286 that the $\mathrm{A} / \mathrm{P}$ ratio in rumen fermentation was a good indicator of milk fat synthesis and 287 acidification (NRC, 2001). In this experiment, as decreasing A/P ratio in the rumen, it considers 288 that a high level of SSB supplementation could increase milk yield but might affect rumen 289 acidification and negative effect on feed utilization (Russell, 1998). 
In the rumen in vitro digestibility trial, the negative effects of SSB supplementation did not

291 significantly observe in the $2 \%$ supplementation group. When feeding $4.0 \%$ of DM SSB, the

292 negative effects of SSB supplementation were significantly observed during rumen in vitro

293 digestibility. When describing the biological action of microorganisms mathematically, the

294 sigmoid function is generally used. The gas production was predicted as $96.96 \%$ using a fitted

295 sigmoid curve when feeding 3.0\% of DM SSB in the rumen in vitro digestibility test (see table

296 5). Thus, we decided to feed $3.0 \%$ of DM SSB in the feeding trial. In the feeding trial, as fed

297 TMR including 3.0\% of DM of SSB, the performance did not show a significant difference in the

298 DMI, milk production, and milk composition compared with those of control. In the in vitro trial,

299 the A/P ratio was decreased as an increase SSB, which could mean that the digestibility of

300 fibrous materials was lower than those of non-fibrous material in the SSB. The decrease of the

$301 \mathrm{~A} / \mathrm{P}$ ratio in the rumen has an effect on an increasing milk yield of lactating cow (Sutton et al.,

302 2003), the milk yield did not show a significant difference between treatments during the feeding

303 trial. This result considers that the NDF and ADF fraction in the SSB seems to play a sufficient

304 role as roughage in the rumen. Furthermore, in the milk productivity and blood profiles, it did

305 not show a negative effect with fed 3.0\% DM of SSB on the lactating cows. Although the SSB

306 has disadvantages such as high silica contained ash content, high EE content, and low nutritional

307 uniformity, it has enough proper CP content and good gross energy as a feed ingredient (see

308 table 1). High levels of silica and fat content in the SSB can reduce the risk by reducing the fed

309 amount to the ruminant. Furthermore, about 12,000 tons of starch sugar by-products are dumped

310 per year in South Korea (Seonoh. Park et al., 2017), if approximately 0.5 percent of the TMR

311 will substitute as the SSB, all of them can be recycled. If the proper amount of SSB is used for

312 animal feed ingredients, it could be diminished not only the environmental pollution but 
313 economic loss by saving the budget for disposal. In this study, 3.0\% DM of SSB in TMR did not 314 negatively affect the milk production of lactating cows, which makes it a reasonable suggestion 315 for feeding levels. 


\section{Conclusions}

318 The SSB levels of $3.0 \%$ of DM in the diet can be used for the lactating cow without adverse

319 effects on milk productivity and blood profile. However, the SSB might have some negative

320 effects on the ruminant when dietary levels of SSB were increased to $3.0 \%$ of DM due to high

321 silica-contained ash and high EE content. On the other hand, the SSB has proper CP content and

322 good gross energy as a feed ingredient. Therefore, the TMR contained 3.0\% of DM of SSB can

323 be used in the lactating cows as an energy and protein source without adverse effects. 


\section{Acknowledgements}

326 This research was supported by Basic Science Research Program through the National Research

327 Foundation of Korea (NRF) funded by the Ministry of Education (2021R1I1A1A01058751). 
329

330

331

332

333

334

335

336

337

338

339

340

341

342

343

344

345

346

347

348

349

350

351

352

353

354

355

356

357

358

359

360

361

362

\section{References}

AOAC. 2005. Official methods of analysis of AOAC International 18th edition. Available from: http://www.worldcat.org/title/official-methods-of-analysis-of-aoac-international/oclc/62751475

Bocquier, F., and E. González-García. 2010. Sustainability of ruminant agriculture in the new context: feeding strategies and features of animal adaptability into the necessary holistic approach. Animal. 4:1258-1273. doi:10.1017/S1751731110001023.

Chaney, A. L., and E. P. Marbach. 1962. Modified Reagents for Determination of Urea and Ammonia. Clin. Chem. 8:130-132. doi:10.1093/clinchem/8.2.130.

Choi, Y., J. Rim, H. Lee, H. Kwon, Y. Na, and S. Lee. 2019. Effect of fermented spent instant coffee grounds on milk productivity and blood profiles of lactating dairy cows. Asian-Australas. J. Anim. Sci. 32:1007-1014. doi:10.5713/ajas.18.0846.

Dijkstra, J., J. L. Ellis, E. Kebreab, A. B. Strathe, S. Lopez, J. France, and A. Bannink. 2012. Ruminal $\mathrm{pH}$ regulation and nutritional consequences of low pH. Anim. Feed Sci. Technol. 172:22-33.

Floch, J. 1957. A simple method for the isolation and purification of total lipids from animal tissues. J Biol Chem. 226:497-509.

Gaffney, S. 2008. Corn Refiners Association (http://www. corn. org). J. Agric. Food Inf. 9:94100 .

Garces, R., and M. Mancha. 1993. One-Step Lipid Extraction and Fatty Acid Methyl Esters Preparation from Fresh Plant Tissues. Anal. Biochem. 211:139-143. doi:10.1006/abio.1993.1244.

Harmon, D. L., R. M. Yamka, and N. A. Elam. 2004. Factors affecting intestinal starch digestion in ruminants: A review. Can. J. Anim. Sci. 84:309-318.

Henderson, J. W., R. D. Ricker, B. A. Bidlingmeyer, and C. Woodward. 2000. Rapid, accurate, sensitive, and reproducible HPLC analysis of amino acids. Amino Acid Anal. Using Zorbax Eclipse-AAA Columns Agil. 1100:1-10.

Heuzé, V., G. Tran, and S. Kaushik. 2015. Soybean meal. Feed. Org Programme INRA CIRAD AFZ FAO Available Online Httpwww Feed. Orgnode674.

Hristov, A. N., and J. K. Ropp. 2003. Effect of dietary carbohydrate composition and availability on utilization of ruminal ammonia nitrogen for milk protein synthesis in dairy cows. J. Dairy Sci. $86: 2416-2427$.

Huntington, G. B. 1997. Starch utilization by ruminants: from basics to the bunk. J. Anim. Sci. $75: 852-867$.

James, G. 2008. Sugarcane. John Wiley \& Sons. 
363 Jarvis, G. N., and E. R. B. Moore. 2010. 46 Lipid Metabolism and the Rumen Microbial

364 Ecosystem.

365 Johnson, K. A., and D. E. Johnson. 1995. Methane emissions from cattle. J. Anim. Sci. 73:24833662492.

367 Kato, S. 1993. Filter cake scraping method and rotary drum filter using the same. Available

368 from: https://patents.google.com/patent/US5262069A/en

369 Kerepesi, I., M. Toth, and L. Boross. 1996. Water-soluble carbohydrates in dried plant. J. Agric.

370 Food Chem. 44:3235-3239.

371 Lepage, G., and C. C. Roy. 1986. Direct transesterification of all classes of lipids in a one-step

372 reaction. J. Lipid Res. 27:114-120. doi:10.1016/S0022-2275(20)38861-1.

373 McDougall, E. I. 1948. Studies on ruminant saliva. 1. The composition and output of sheep's

374 saliva. Biochem. J. 43:99-109.

375 Menke, K. H., L. Raab, A. Salewski, H. Steingass, D. Fritz, and W. Schneider. 1979. The 376 estimation of the digestibility and metabolizable energy content of ruminant feedingstuffs from

377 the gas production when they are incubated with rumen liquor in vitro. J. Agric. Sci. 93:217-222.

378

379

380

381

382

383

384

385

386

387

388

389

390

391

392

393

394

395

Mills, J. a. N., J. France, and J. Dijkstra. 1999. A review of starch digestion in the lactating dairy cow and proposals for a mechanistic model: 1. Dietary starch characterisation and ruminal starch digestion. J. Anim. Feed Sci. 8:291-340. doi:10.22358/jafs/68938/1999.

Nielsen, S. S. 2017. Total carbohydrate by phenol-sulfuric acid method. In: Food analysis laboratory manual. Springer. p. 137-141.

NRC, N. R. 2001. Nutrient requirements of dairy cattle: 2001. National Academies Press.

Ortega Cerrilla, M. E., and G. Mendoza Martínez. 2003. Starch digestion and glucose metabolism in the ruminant: a review. Interciencia. 28:380-386.

Rabelo, S. C., A. C. da Costa, and C. E. Vaz Rossel. 2015. Chapter 17 - Industrial Waste Recovery. In: F. Santos, A. Borém, and C. Caldas, editors. Sugarcane. Academic Press, San Diego. p. 365-381. Available from:

https://www.sciencedirect.com/science/article/pii/B9780128022399000177

Russell, J. B. 1998. The Importance of $\mathrm{pH}$ in the Regulation of Ruminal Acetate to Propionate Ratio and Methane Production In Vitro. J. Dairy Sci. 81:3222-3230. doi:10.3168/jds.S00220302(98)75886-2.

Seonoh. Park, GilJong, Oh, and Kiheon, Kim. 2017. Material flow analysis of animal-plant residues generated by the food manufacturing industry. J Korea Soc. Waste Manag. 34:657-667. doi:10.9786/kswm.2017.34.7.657. 
396 Silva, B. C., M. V. C. Pacheco, L. A. Godoi, F. a. S. Silva, D. Zanetti, A. C. B. Menezes, P.

397 Pucetti, S. A. Santos, M. F. Paulino, and S. C. V. Filho. 2020. In situ and in vitro techniques for 398 estimating degradation parameters and digestibility of diets based on maize or sorghum. J. Agric.

399 Sci. 158:150-158. doi:10.1017/S0021859620000271.

400 Soest, P. J. V. 1994. Nutritional Ecology of the Ruminant. Cornell University Press.

401 Sutton, J. D., M. S. Dhanoa, S. V. Morant, J. France, D. J. Napper, and E. Schuller. 2003. Rates 402 of Production of Acetate, Propionate, and Butyrate in the Rumen of Lactating Dairy Cows Given 403 Normal and Low-Roughage Diets. J. Dairy Sci. 86:3620-3633. doi:10.3168/jds.S0022404 0302(03)73968-X.

405 Svihus, B., A. K. Uhlen, and O. M. Harstad. 2005. Effect of starch granule structure, associated 406 components and processing on nutritive value of cereal starch: A review. Anim. Feed Sci.

407 Technol. 122:303-320. doi:10.1016/j.anifeedsci.2005.02.025.

408 Theodorou, M. K., B. A. Williams, M. S. Dhanoa, A. B. McAllan, and J. France. 1994. A simple 409 gas production method using a pressure transducer to determine the fermentation kinetics of 410 ruminant feeds. Anim. Feed Sci. Technol. 48:185-197.

411 Van Soest, P. J., J. B. Robertson, and B. A. Lewis. 1991. Methods for Dietary Fiber, Neutral 412 Detergent Fiber, and Nonstarch Polysaccharides in Relation to Animal Nutrition. J. Dairy Sci. 413 74:3583-3597. doi:10.3168/jds.S0022-0302(91)78551-2.

414 Younes, M., P. Aggett, F. Aguilar, R. Crebelli, B. Dusemund, M. Filipič, M. J. Frutos, P. Galtier, 415 D. Gott, and U. Gundert-Remy. 2018. Re-evaluation of Silicon Dioxide (E 551) as a Food 416 Additive. EFSA J. Eur. Food Saf. Auth. 16:e05088. 
Figure 1

Starch sugar by-product (SSB) producing process

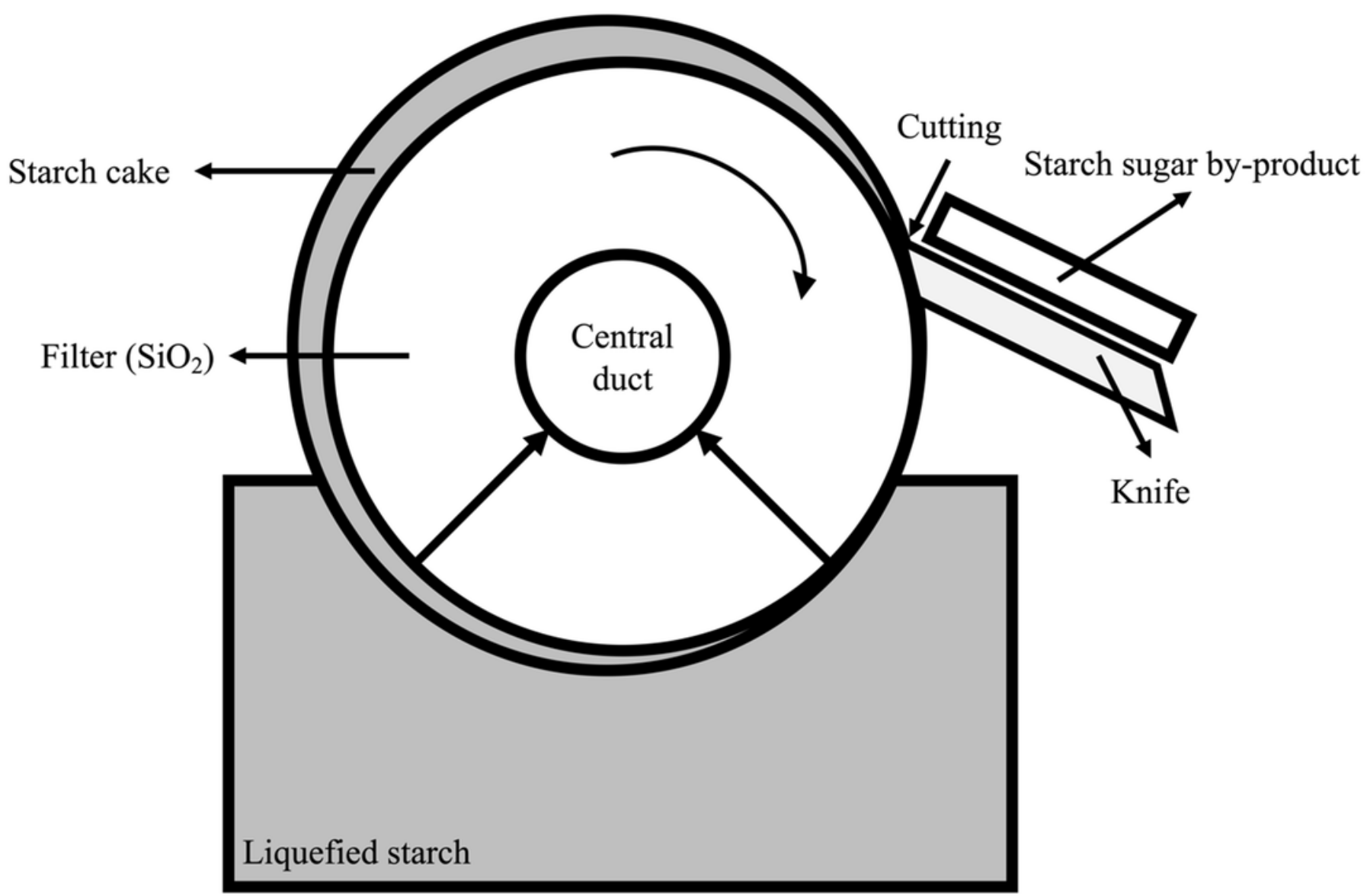




\section{Table $\mathbf{1}$ (on next page)}

Physical and chemical characteristics of starch sugar by-product 
1 Table 1:

2 Physical and chemical characteristics of starch sugar by-product

\begin{tabular}{|c|c|c|c|c|c|c|c|c|c|}
\hline Items & Mean & Median & $\mathrm{SD}$ & MIN & MAX & Skewness $^{1}$ & $2 \times \mathrm{SE}_{\mathrm{S}}{ }^{2}$ & Kurtosis $^{3}$ & $2 \times \mathrm{SE}_{\mathrm{k}}{ }^{4}$ \\
\hline \multicolumn{10}{|l|}{ Physical characteristics } \\
\hline Complex viscosity $(\mathrm{hPa} / \mathrm{s})$ & 133.98 & 118.39 & 50.29 & 75.36 & 212.35 & 0.29 & 1.55 & -1.48 & 3.10 \\
\hline Particle, size $(\mu \mathrm{m})$ & 557 & 570 & 128 & 289 & 703 & -1.16 & 1.55 & 1.07 & 3.10 \\
\hline Density $\left(\mathrm{DM} \mathrm{g} / \mathrm{cm}^{3}\right)$ & 1.31 & 1.26 & 0.14 & 1.19 & 1.61 & 1.15 & 1.55 & 0.71 & 3.10 \\
\hline \multicolumn{10}{|l|}{ Chemical compositions ${ }^{5}$} \\
\hline $\mathrm{DM}(\%)$ & 61.43 & 61.80 & 3.52 & 55.20 & 65.83 & -0.44 & 1.55 & -0.79 & 3.10 \\
\hline $\mathrm{CP}(\% \mathrm{DM})$ & 14.43 & 13.00 & 7.63 & 6.01 & 33.46 & 1.93 & 1.55 & 4.57 & 3.10 \\
\hline $\mathrm{EE}(\% \mathrm{DM})$ & 23.26 & 21.40 & 7.41 & 10.66 & 36.99 & 0.22 & 1.55 & 0.42 & 3.10 \\
\hline NDF (\%DM) & 35.67 & 34.10 & 11.28 & 13.15 & 51.22 & -0.76 & 1.55 & 0.66 & 3.10 \\
\hline $\mathrm{ADF}(\% \mathrm{DM})$ & 31.29 & 28.93 & 10.93 & 11.76 & 47.11 & -0.20 & 1.55 & -0.12 & 3.10 \\
\hline Ash (\%DM) & 32.60 & 33.68 & 13.67 & 11.01 & 57.32 & 0.20 & 1.55 & -0.06 & 3.10 \\
\hline $\mathrm{SiO}_{2}(\% \mathrm{DM})$ & 30.54 & 31.55 & 12.81 & 10.31 & 53.70 & 0.18 & 1.55 & -0.05 & 3.10 \\
\hline WSC (\%DM) & 9.96 & 9.22 & 3.98 & 1.71 & 15.78 & -0.48 & 1.55 & 1.37 & 3.10 \\
\hline GE (Kcal/kg) & 4,198 & 3965 & 1,033 & 2,341 & 6,005 & 0.11 & 1.55 & 0.48 & 3.10 \\
\hline $\mathrm{pH}$ & 4.14 & 3.71 & 0.80 & 3.41 & 5.33 & 0.97 & 1.55 & -1.22 & 3.10 \\
\hline
\end{tabular}

3 DM, dry matter; CP, crude protein; EE, ether extract; NDF, neutral detergent fiber; ADF, acid detergent fiber; WSC, water

4 soluble carbohydrate; GE, gross energy; SD, Standard deviation; MIN, Minimum value in database, MAX, Maximum value in 5 database.

$6{ }^{1}$ The degree of asymmetry of a distribution around its mean where $0 \pm 2 \times \mathrm{Se}_{\mathrm{S}}=$ normal.

$7 \quad{ }^{2} \mathrm{SE}_{\mathrm{S}}$, square $\operatorname{root}(6 / \mathrm{n})$.

$8{ }^{3}$ Characterizes the relative peakedness or flatness of a distribution, where $0 \pm 2 \times$ Sek $=$ normal.

$9{ }^{4} \mathrm{SEk}_{\mathrm{k}}$, square root $(24 / \mathrm{n})$.

$10{ }^{5} \mathrm{ADF}$ and $\mathrm{SiO} 2$ were analyzed to be residues left over following the analysis of NDF and ash, respectively. 


\section{Table 2 (on next page)}

Ingredients and nutritional composition of different level of starch sugar by-product substrate on ruminal in vitro digestibility 
1 Table 2:

2 Ingredients and nutritional composition of different level of starch sugar by-product substrate on

3 ruminal in vitro digestibility

\begin{tabular}{lrrrrr}
\hline & \multicolumn{5}{c}{ SSB level (\%DM) } \\
\cline { 2 - 6 } Items & \multicolumn{6}{c}{ 0 } & 2 & \multicolumn{1}{c}{4} & 6 & 8 \\
\hline Ingredients (\%DM) & 30.00 & 30.00 & 30.00 & 30.00 & 30.00 \\
Timothy & 10.00 & 10.00 & 10.00 & 10.00 & 10.00 \\
Beet pulp & 40.00 & 38.20 & 36.40 & 34.60 & 32.80 \\
Corn & 0.00 & 2.00 & 4.00 & 6.00 & 8.00 \\
Starch sugar by-product & 20.00 & 19.80 & 19.60 & 19.40 & 19.20 \\
Soybean meal & & & & & \\
Chemical composition & 16.82 & 16.82 & 16.82 & 16.82 & 16.82 \\
CP (\%DM) & 2.78 & 3.15 & 3.52 & 3.89 & 4.26 \\
EE (\%DM) & 55.72 & 55.45 & 55.18 & 54.92 & 54.65 \\
NDF (\%DM) & 25.61 & 26.08 & 26.56 & 27.03 & 27.51 \\
ADF (\%DM) & 4.99 & 5.48 & 5.98 & 6.48 & 6.97 \\
Ash (\%DM) & 4,438 & 4428 & 4418 & 4408 & 4399 \\
GE (kcal/kg) &
\end{tabular}

4 SSB, starch sugar by-product; CP, crude protein; EE, ether extract; NDF, neutral detergent fiber;

5 ADF, acid detergent fiber; GE, gross energy.

6 


\section{Table 3 (on next page)}

Formulation and chemical composition of control and starch sugar by-product diet in dairy lactating cows 
1 Table 3:

2 Formulation and chemical composition of control and starch sugar by-product diet in dairy

3 lactating cows

\begin{tabular}{|c|c|c|}
\hline Items & Control & SSB \\
\hline \multicolumn{3}{|l|}{ Ingredient $(\%)$} \\
\hline Commercial mixed feed ${ }^{1}$ & 21.31 & 21.31 \\
\hline Molasses & 2.16 & 2.16 \\
\hline Corn, flacked & 4.26 & 4.26 \\
\hline Corn gluten feed & 1.99 & 1.99 \\
\hline Wheat bran & 1.99 & 1.99 \\
\hline Rice bran & 4.97 & 1.39 \\
\hline SSBP & - & 4.00 \\
\hline Beetpulp pellet & 3.41 & 4.55 \\
\hline Cotton seed & 4.97 & 4.97 \\
\hline Browers grain, wet & 9.23 & 9.23 \\
\hline Alfalfa hay & 8.10 & 8.10 \\
\hline Oat hay & 4.26 & 4.26 \\
\hline Timothy hay & 7.39 & 7.39 \\
\hline Bermuda grass hay & 2.84 & 2.84 \\
\hline Klein grass hay & 2.84 & 2.84 \\
\hline Elvan & 0.26 & - \\
\hline Water & 20.02 & 18.72 \\
\hline Total & 100.00 & 100.00 \\
\hline \multicolumn{3}{|l|}{ Chemical composition } \\
\hline $\operatorname{DM}(\%)$ & 64.99 & 64.96 \\
\hline Forage ratio (\%DM) & 39.12 & 39.14 \\
\hline $\mathrm{NEL}^{2}$ (Mcal/kg DM) & 1.69 & 1.69 \\
\hline $\mathrm{TDN}^{2}(\% \mathrm{DM})$ & 73.87 & 73.87 \\
\hline CP (\%DM) & 16.57 & 16.34 \\
\hline $\mathrm{EE}(\% \mathrm{DM})$ & 5.38 & 5.38 \\
\hline NFC (\%DM) & 29.61 & 29.44 \\
\hline CF (\%DM) & 17.55 & 17.45 \\
\hline NDF (\%DM) & 40.86 & 40.98 \\
\hline $\mathrm{ADF}(\% \mathrm{DM})$ & 23.78 & 23.78 \\
\hline Ash (\%DM) & 7.90 & 7.90 \\
\hline
\end{tabular}

4 SSB, starch sugar by-product; DM, dry matter, NEL, net energy for lactation; TDN, total digestible 5 nutrient; CP, crude protein, EE, ether extract; NFC, non-fibrous carbohydrate; NDF, neutral 6 detergent fiber, ADF, acid detergent fiber

$7{ }^{1}$ Commercial mixed feed formula, Corn grain 30.0\%; Molasses 5.0\%; Soybean meal 22.2\%; 8 Rapeseed meal 7\%; Corn gluten feed 10.0\%; Copra meal 5.6\%; Parm oil meal 15.0\%; Limestone $92.3 \%$; Salt 0.8\%; Sodium bicarbonate 0.8\%; By-pass fat 0.3\%; Vit \& Mineral premix 1.0\%.

$10 \quad 2 \mathrm{NEL}$ and TDN was calculated by NRC 2001 model. 


\section{Table 4 (on next page)}

Changes of in situ dry matter and crude protein disappearance rate of starch sugar byproduct and corn in the rumen 
1 Table 4:

2 Changes of in situ dry matter and crude protein disappearance rate of

3 starch sugar by-product and corn in the rumen

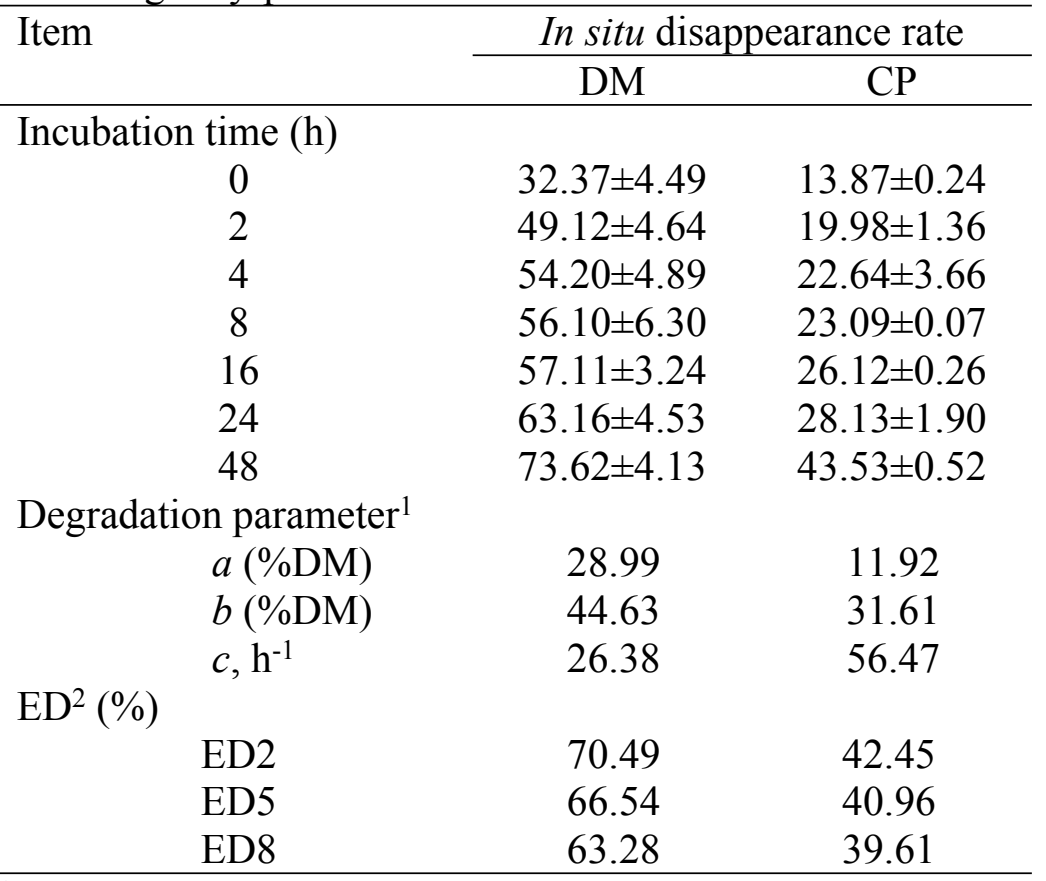

$4 \overline{\mathrm{a}}$, water soluble fraction which is rapidly washed out of bags and

5 assumed to be completely degradable; b, the slowly degradable

6 fraction; c, the rate of degradation per hour.

$7 \quad{ }^{2} \mathrm{ED}$, effective degradability; A fractional rate of passage out of the

8 rumen, which was assumed as $0.02,0.05$ and $0.08 / \mathrm{h}$.

9 


\section{Table 5 (on next page)}

Effect of starch sugar by-product on ruminal in vitro gas production, $\mathrm{pH}$, and ammonia nitrogen 
1 Table 5:

2 Effect of starch sugar by-product on ruminal in vitro gas production, $\mathrm{pH}$, and ammonia nitrogen

\begin{tabular}{|c|c|c|c|c|c|c|c|}
\hline \multirow[b]{2}{*}{ Incubation time $(\mathrm{h})$} & \multicolumn{5}{|c|}{ SSB (\%DM) } & \multirow[b]{2}{*}{ SEM } & \multirow[b]{2}{*}{$p$-value } \\
\hline & 0 & 2 & 4 & 6 & 8 & & \\
\hline \multicolumn{8}{|c|}{ Gas production, $\mathrm{ml}$} \\
\hline 0 & 0.00 & 0.00 & 0.00 & 0.00 & 0.00 & - & - \\
\hline 2 & 13.00 & 12.33 & 11.33 & 10.67 & 9.00 & 1.10 & 0.17 \\
\hline 4 & 20.33 & 20.00 & 21.33 & 20.00 & 17.33 & 1.10 & 0.16 \\
\hline 8 & $36.00^{\mathrm{a}}$ & $31.67^{\mathrm{b}}$ & $29.67^{b c}$ & $26.33^{\mathrm{cd}}$ & $22.33^{\mathrm{d}}$ & 0.87 & $<0.01$ \\
\hline 16 & $64.67^{\mathrm{ab}}$ & $67.33^{\mathrm{a}}$ & $56.00^{\mathrm{ab}}$ & $64.00^{\mathrm{b}}$ & $52.00^{\mathrm{b}}$ & 2.86 & 0.01 \\
\hline 24 & 69.67 & 65.00 & 68.67 & 67.33 & 63.33 & 2.86 & 0.27 \\
\hline $48^{1}$ & $96.67^{\mathrm{a}}$ & $97.33^{\mathrm{a}}$ & $\begin{array}{c}79.33^{b} \\
\mathrm{pH}\end{array}$ & $81.33^{\mathrm{b}}$ & $81.67^{\mathrm{b}}$ & 1.50 & $<0.01$ \\
\hline 0 & 6.90 & 6.90 & 6.90 & 6.90 & 6.90 & - & - \\
\hline 2 & 6.99 & 7.06 & 7.03 & 7.00 & 7.02 & 0.03 & 0.49 \\
\hline 4 & 6.96 & 6.97 & 7.00 & 6.97 & 6.91 & 0.03 & 0.29 \\
\hline 8 & $6.76^{\mathrm{ab}}$ & $6.83^{\mathrm{a}}$ & $6.75^{b}$ & $6.80^{\mathrm{ab}}$ & $6.78^{\mathrm{ab}}$ & 0.01 & 0.03 \\
\hline 16 & 6.59 & 6.60 & 6.64 & 6.65 & 6.63 & 0.02 & 0.08 \\
\hline 24 & 6.55 & 6.52 & 6.58 & 6.56 & 6.55 & 0.02 & 0.25 \\
\hline 48 & $6.50^{\mathrm{a}}$ & $6.44^{\mathrm{ab}}$ & $6.47^{\mathrm{ab}}$ & $6.42^{\mathrm{b}}$ & $6.45^{\mathrm{ab}}$ & 0.01 & 0.02 \\
\hline \multicolumn{8}{|c|}{ Ammonia nitrogen $(\mathrm{mg} / 100 \mathrm{ml})$} \\
\hline 0 & 0.50 & 0.50 & 0.50 & 0.50 & 0.50 & - & - \\
\hline 2 & $1.11^{\mathrm{a}}$ & $1.27^{\mathrm{a}}$ & $1.27^{\mathrm{a}}$ & $0.73^{b}$ & $0.59^{b}$ & 0.04 & $<0.01$ \\
\hline 4 & $0.62^{\mathrm{a}}$ & $0.54^{\mathrm{ab}}$ & $0.54^{\mathrm{ab}}$ & $0.40^{\mathrm{b}}$ & $0.40^{\mathrm{b}}$ & 0.05 & 0.03 \\
\hline 8 & 0.82 & 0.59 & 0.48 & 0.48 & 0.43 & 0.10 & 0.14 \\
\hline 16 & $0.93^{\mathrm{a}}$ & $0.83^{a}$ & $0.83^{\mathrm{a}}$ & $0.63^{b}$ & $0.66^{b}$ & 0.06 & 0.03 \\
\hline 24 & $4.09^{a}$ & $4.03^{\mathrm{a}}$ & $3.45^{\mathrm{a}}$ & $2.01^{\mathrm{b}}$ & $2.15^{b}$ & 0.18 & $<0.01$ \\
\hline 48 & 5.44 & 5.38 & 5.22 & 4.94 & 5.25 & 0.29 & 0.77 \\
\hline
\end{tabular}

3 SSB, starch sugar by-product; SEM, standard error of the mean.

4 abcdMeans in the same row with different superscrips differ significantly $(\mathrm{P}<0.05)$.

5 II had sigmoidally decreased as an increase SSB level (Equation, Y $=80.78+\frac{16.22}{\left[1+\left(\frac{x}{3.77}\right)^{34.89}\right]^{10.53}}$,

$\left.6 \quad \mathrm{R}^{2}=0.989\right)$.

7 
Table 6(on next page)

Effect of starch sugar by-product on ruminal in vitro volatile fatty acid synthesis 
1 Table 6:

2 Effect of starch sugar by-product on ruminal in vitro volatile fatty acid synthesis

\begin{tabular}{|c|c|c|c|c|c|c|c|}
\hline \multirow[b]{2}{*}{ Incubation time $(\mathrm{h})$} & \multicolumn{5}{|c|}{ SSB (\%DM) } & \multirow[b]{2}{*}{ SEM $^{1}$} & \multirow[b]{2}{*}{ p-value } \\
\hline & 0 & 2 & 4 & 6 & 8 & & \\
\hline \multicolumn{8}{|c|}{-------- Total VFA (mM) -------- } \\
\hline 0 & 22.26 & 22.26 & 22.26 & 22.26 & 22.26 & 2.03 & - \\
\hline 2 & 22.47 & 23.00 & 22.43 & 23.07 & 24.05 & 0.63 & 0.41 \\
\hline 4 & 29.89 & 30.94 & 30.63 & 31.89 & 30.52 & 1.53 & 0.92 \\
\hline 8 & 41.02 & 41.61 & 43.67 & 41.80 & 40.88 & 1.21 & 0.53 \\
\hline 16 & 61.69 & 62.08 & 60.84 & 57.56 & 57.28 & 2.14 & 0.39 \\
\hline 24 & 66.85 & 69.76 & 67.46 & 68.18 & 67.18 & 3.35 & 0.97 \\
\hline 48 & 82.31 & 81.07 & 87.81 & 84.13 & 86.28 & 2.58 & 0.39 \\
\hline \multicolumn{8}{|c|}{------------ Acetate (mM) ----------- } \\
\hline 0 & 13.21 & 13.21 & 13.21 & 13.21 & 13.21 & 0.99 & - \\
\hline 2 & 13.38 & 13.67 & 13.22 & 13.71 & 14.25 & 0.39 & 0.44 \\
\hline 4 & 17.64 & 18.16 & 17.91 & 18.69 & 17.73 & 0.81 & 0.89 \\
\hline 8 & 23.38 & 23.74 & 24.62 & 23.30 & 22.74 & 066 & 0.41 \\
\hline 16 & 33.65 & 33.29 & 32.21 & 30.53 & 29.98 & 1.10 & 0.14 \\
\hline 24 & 35.64 & 36.22 & 35.60 & 35.48 & 34.56 & 1.73 & 0.97 \\
\hline 48 & 43.13 & 41.98 & 45.02 & 43.15 & 43.59 & 1.30 & 0.60 \\
\hline \multicolumn{8}{|c|}{-------- Propionate (mM) -------- } \\
\hline 0 & 5.47 & 5.47 & 5.47 & 5.47 & 5.47 & 0.49 & - \\
\hline 2 & 5.72 & 5.79 & 5.64 & 5.84 & 6.13 & 0.18 & 0.40 \\
\hline 4 & 7.69 & 7.99 & 7.85 & 8.32 & 8.04 & 0.54 & 0.94 \\
\hline 8 & 11.34 & 11.43 & 12.63 & 12.04 & 12.06 & 0.45 & 0.31 \\
\hline 16 & 18.60 & 18.58 & 19.07 & 18.22 & 18.76 & 0.79 & 0.96 \\
\hline 24 & 20.57 & 22.32 & 21.41 & 22.44 & 22.80 & 1.26 & 0.72 \\
\hline 48 & 25.12 & 25.30 & 28.24 & 27.91 & 29.02 & 1.01 & 0.06 \\
\hline \multicolumn{8}{|c|}{-------- A/P ratio ------------ } \\
\hline 0 & 2.42 & 2.42 & 2.42 & 2.42 & 2.42 & 0.04 & - \\
\hline 2 & 2.34 & 2.36 & 2.34 & 2.35 & 2.33 & 0.02 & 0.72 \\
\hline 4 & 2.30 & 2.28 & 2.28 & 2.27 & 2.21 & 0.05 & 0.75 \\
\hline 8 & $2.06^{\mathrm{ab}}$ & $2.08^{\mathrm{a}}$ & $1.95^{\mathrm{bc}}$ & $1.94^{\mathrm{c}}$ & $1.89^{c}$ & 0.02 & $<0.01$ \\
\hline 16 & $1.81^{\mathrm{a}}$ & $1.79^{\mathrm{a}}$ & $1.70^{\mathrm{ab}}$ & $1.68^{\mathrm{ab}}$ & $1.60^{b}$ & 0.04 & 0.01 \\
\hline 24 & $1.73^{\mathrm{a}}$ & $1.63^{\mathrm{abc}}$ & $1.66^{\mathrm{ab}}$ & $1.58^{\mathrm{bc}}$ & $1.52^{\mathrm{c}}$ & 0.03 & 0.01 \\
\hline 48 & $1.72^{\mathrm{a}}$ & $1.66^{\mathrm{ab}}$ & $1.60^{\mathrm{ab}}$ & $1.54^{\mathrm{ab}}$ & $1.50^{\mathrm{b}}$ & 0.04 & 0.02 \\
\hline
\end{tabular}

3 SSB, starch sugar by-product; SEM, standard error of the mean; VFA, volatile fatty acid; A/P 4 ratio, acetate to propionate ratio.

$5 \quad{ }^{a b c}$ Means in the same row with different superscrips differ significantly $(\mathrm{P}<0.05)$. 


\section{Table 7 (on next page)}

Dry matter intake, milk production and composition of dairy lactating cows fed the control and starch sugar by-product diet 
1 Table 7:

2 Dry matter intake, milk production and composition of dairy lactating cows fed the control and

3 starch sugar by-product diet

\begin{tabular}{|c|c|c|c|c|}
\hline Items & Control & $\mathrm{SSB}^{1}$ & SEM & P-value \\
\hline Dry matter intake (kg/cows/day) & 27.47 & 24.52 & 0.47 & 0.45 \\
\hline \multicolumn{5}{|l|}{ Milk production } \\
\hline Milk yield (kg/cow/day) & 29.01 & 30.02 & 0.94 & 0.46 \\
\hline $4 \% \mathrm{FCM}^{2}(\mathrm{~kg} / \mathrm{cow} /$ day $)$ & 29.45 & 32.06 & 1.14 & 0.14 \\
\hline $\operatorname{FPCM}^{3}(\mathrm{~kg} /$ cow/day $)$ & 29.45 & 31.47 & 1.06 & 0.47 \\
\hline \multicolumn{5}{|l|}{ Milk composition } \\
\hline Fat $(\%)$ & 4.13 & 4.45 & 0.18 & 0.21 \\
\hline Protein $(\%)$ & 3.36 & 3.25 & 0.06 & 0.22 \\
\hline Lactose $(\%)$ & 4.64 & 4.78 & 0.05 & 0.06 \\
\hline Solid not fat (\%) & 8.79 & 8.73 & 0.06 & 0.47 \\
\hline Milk urea nitrogen $(\mathrm{ng} / \mathrm{ml})$ & 11.20 & 11.78 & 0.49 & 0.36 \\
\hline Somatic cell counts $\left(10^{3}\right.$ cell $\left./ \mathrm{ml}\right)$ & 273.67 & 192.75 & 115.23 & 0.39 \\
\hline
\end{tabular}

4 SSB, starch sugar by-product; SEM, Standard error of the mean.

$5{ }^{1}$ Replacement of 3.0\% DM of SSB in total mixed ration.

$624 \%$ Fat corrected milk $(4 \% \mathrm{FCM})$ was calculated from $4 \% \mathrm{FCM}=0.4 \times$ milk yield $+15 \times$ milk fat 7 yield.

$8{ }^{3}$ Fat-protein corrected milk $($ FPCM $)$ was calculated from FPCM $=$ milk yield $\times(0.337+0.116 \times$ 9 milk fat $(\%)+0.06 \times$ milk protein $(\%)$. 


\section{Table 8(on next page)}

Blood profiles of lactating dairy cows fed the control and starch sugar by-product diet 
1 Table 8:

2 Blood profiles of lactating dairy cows fed the control and starch sugar by-product diet

\begin{tabular}{lrrrc}
\hline Items & Control & SSB $^{1}$ & SEM & P-value \\
\hline Glucose $(\mathrm{mg} / \mathrm{dL})$ & 37.44 & 30.19 & 2.89 & 0.10 \\
BUN $(\mathrm{mg} / \mathrm{dL})$ & 14.38 & 15.08 & 0.50 & 0.34 \\
Cholesterol $(\mathrm{mg} / \mathrm{dL})$ & 296.13 & 291.25 & 25.71 & 0.90 \\
GOT $(\mathrm{IU} / \mathrm{L})$ & 70.25 & 62.25 & 6.56 & 0.40 \\
GPT $(\mathrm{IU} / \mathrm{L})$ & 26.88 & 26.19 & 1.34 & 0.72 \\
GGT $(\mathrm{IU} / \mathrm{L})$ & 38.06 & 31.31 & 2.90 & 0.12 \\
WBC $\left(10^{3} / \mu \mathrm{L}\right)$ & 12.03 & 12.33 & 1.61 & 0.90 \\
RBC $\left(10^{6} / \mu \mathrm{L}\right)$ & 6.19 & 5.93 & 0.20 & 0.38 \\
Hematocrit $(\%)$ & 33.86 & 33.01 & 1.03 & 0.57 \\
Hemoglobin $(\mathrm{g} / \mathrm{dL})$ & 52.60 & 33.38 & 18.55 & 0.31 \\
Platelet $\left(10^{3} / \mu \mathrm{L}\right)$ & 332.00 & 366.31 & 28.39 & 0.41 \\
\hline
\end{tabular}

3 SSB, starch sugar by-product; SEM, standard error of the mean; BUN, blood urea nitrogen; AST,

4 aspartate aminotransferase; ALT, alanine transferase; GGT, $\gamma$-glutamyltransferase; WBC, white

5 blood cell; RBC, red blood cell.

$6{ }^{1}$ Replacement of 3.0\% DM of SSB in total mixed ration.

7 